\title{
ACQUIRED CORNEAL DYSTROPHY* DYSGENESIS OF THE ANTERIOR SEGMENT OF THE EYE, BLUE SCLERAL BAND, OLIGODONTIA, AND METACARPAL DYSPLASIA (DYSPLASIA OCULO-DENTO-DIGITALIS?)
}

\author{
BY \\ HAROLD E. HENKES \\ Eye Hospital, Rotterdam Medical School
}

RIEGER'S dysgenesis mesodermalis iridis et corneae, caused by a faulty differentiation in the anterior segment, is not limited to the mesodermal structures of the eye, but demonstrates a range of ectodermal anomalies as well. This is why Hagedoorn (1937) suggested the term "dysgenesis mesostromalis", stressing the frequent occurrence of ectodermal developmental anomalies of the iris and lens, combined with skeletal and dental anomalies. Dysplasia oculo-dento-digitalis is a syndrome in which, apart from signs of dysgenesis of the anterior segment of the eye, dental and skeletal anomalies are found together with campodactyly and syndactyly. Whether the two syndromes are related is as yet not at all certain, though Frandsen (1964) recently reported a case which he ascribed to each of the two syndromes.

The present paper describes the case of a 16-year-old girl (Fig. 1) suffering from an acute corneal oedema due to a spontaneous (?) descemetolysis in which the question of the underlying developmental anomalies is still not completely cleared.

\section{Case Report}

A 16-year-old girl born in 1948. Her mother had had a normal pregnancy and delivery. The parents and elder brother are normal. Consanguinity in the parents is absent.

The patient has a refractive error of -11.5 sphere bilaterally at least since the age of 7 years. Refraction has not changed since that time. Corrected visual acuity was 7/10 in each eye till 1962 . She did not complain of reduced vision until December, 1962, when she observed a more or less acute loss of vision in the right eye. A definite cause could not be established, though she had been skating and had fallen on her back once or twice.

Visual acuity of the right eye was reduced to hand movements at $1 \mathrm{~m}$. Visual acuity of the left eye with -11.5 sphere was $8 / 10$. The right cornea was almost completely opaque. The picture resembled the acute opacification and swelling of the corneal tissues due to the entrance of aqueous, but signs of keratoconus or hydrophthalmia were lacking. The horizontal diameter of the corneae was $11 \mathrm{~mm}$. and $11.5 \mathrm{~mm}$. in the right eye and left eye respectively. The corneal curvature was measurable only in the left eye. The transparency was completely normal. Sensibility of both corneae was intact. The external scleral sulcus was less marked, giving the eyes a doll's eye appearance.

* Received for publication December 4, 1964 

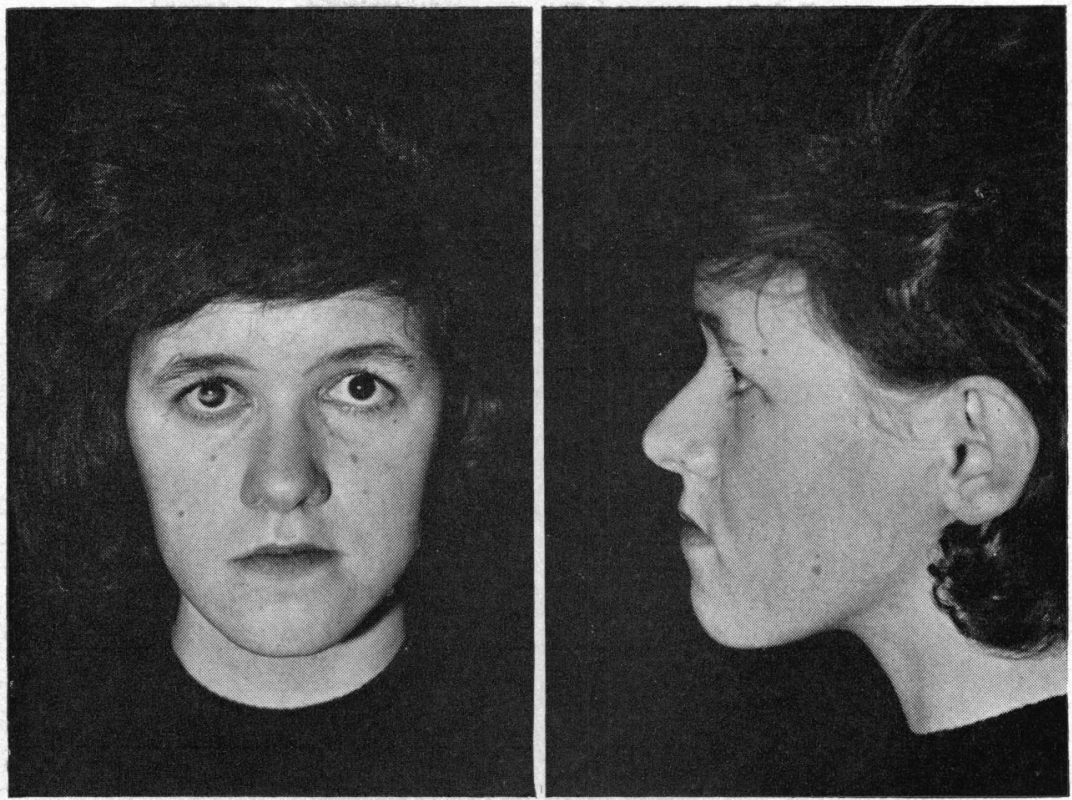

FIG. 1.-The patient, born in 1948 . The photographs were taken at the beginning of 1964.

In the left eye the anterior iris leaf was hypoplastic. (Fig. 2). The pupil was round although some ectopia pupillae was present. The media were clear. The fundus was normal, apart from a temporal cone of the disc.

The intra-ocular pressure was elevated in each eye. It varied in the following months with a maximum in the $25-30 \mathrm{~mm}$. region. The visual field of the left eye was normal. The chamber angle resembled the angle in infantile glaucoma, with an insufficient regression of embryonal mesodermal tissue.

Schwalbe's ring was hyperplastic. A dysplasia marginalis posterior (Streiff), however, was not present. Anterior synechiae were lacking. A thin cobweb-like structure bearing some lumps of pigment could be seen, connected on one side to the hypoplastic iris stroma and on the other, either to the peripheral corneal endothelium, or the ring of Schwalbe.

The sclerae were markedly bluish over the region of the ciliary body and the pars plana (Fig. 3). In this region the sclerae appeared to be both more transparent and thinner, though not of the order of the blue sclerae found in osteogenesis imperfecta.

In the following weeks the periphery of the right cornea cleared considerably and a tearing-off of Descemet's membrane became vaguely visible. There was no adherence, as far as one could see,
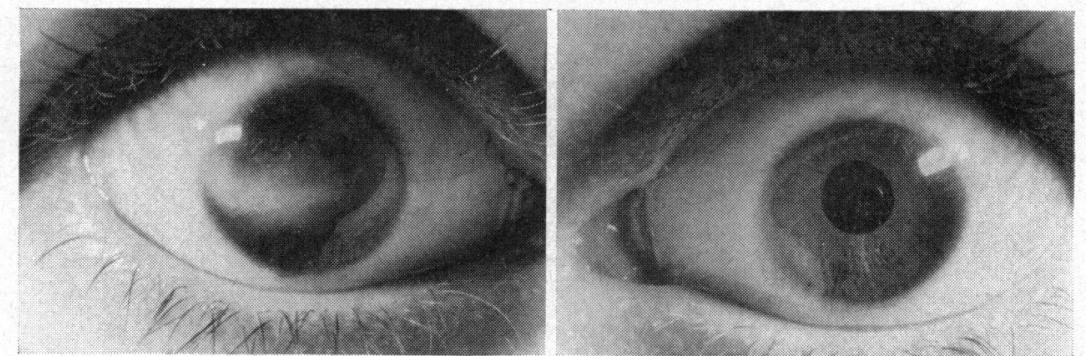

FIG. 2.-Leucoma corneae of right eye, hypoplasia of iris stroma of both eyes, though less visible in right eye. 


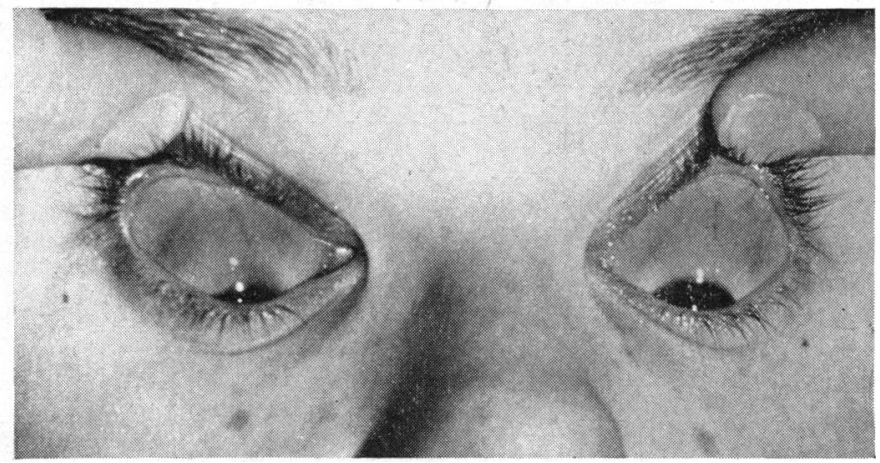

FIG. 3.-Bluish scleral band visible over region of ciliary body and pars plana.

between the descemetolysis and the iris stroma, the latter presenting, as could now be established, the same hypoplastic appearance as in the left eye.

After about 6 weeks the right eye became painful and epithelial dystrophy increased, although it was limited to the central area of the cornea. Intra-ocular pressure now varied considerably. Exact measurements were not possible. Abrasion of the dystrophic corneal epithelium did not improve the condition in the least. Diathermic coagulation of the corneal dystrophy, carried out twice, gave a marked improvement in the following months, although mild corneal vascularization followed. Visual acuity in March, 1964, was recorded as being 1/10. The intra-ocular pressure was then almost normal.

Lens and vitreous were clear, but funduscopy showed cupping of the disc. Although reliable visual field testing was impossible because of the corneal leucoma, a marked loss of field could be detected (Fig. 4). The eye was no longer painful.

During the patient's early childhood the parents had observed a distinct deformity of the skull, particularly of the maxilla. The orthodontist (Dr. J. Weil, Rotterdam), consulted when the child was 9 years old, reported as follows:

"At the external examination a facial anomaly is conspicuous due to a mandibular prognathia and an extreme maxillary micro- and retrognathia. The upper lip is short and hypotonic, the lower lip is curled. Closing of the lips is hardly possible. On masking the upper part of the face above the line between the left and the right orbits the appearance is that of an old woman. The sclerotics of the eyes are notably blue. Internal examination yields the already-mentioned extreme maxillary micro- and retrognathia. This anomaly combined with the mandibular prognathia causes a full mandibular exo-occlusion.

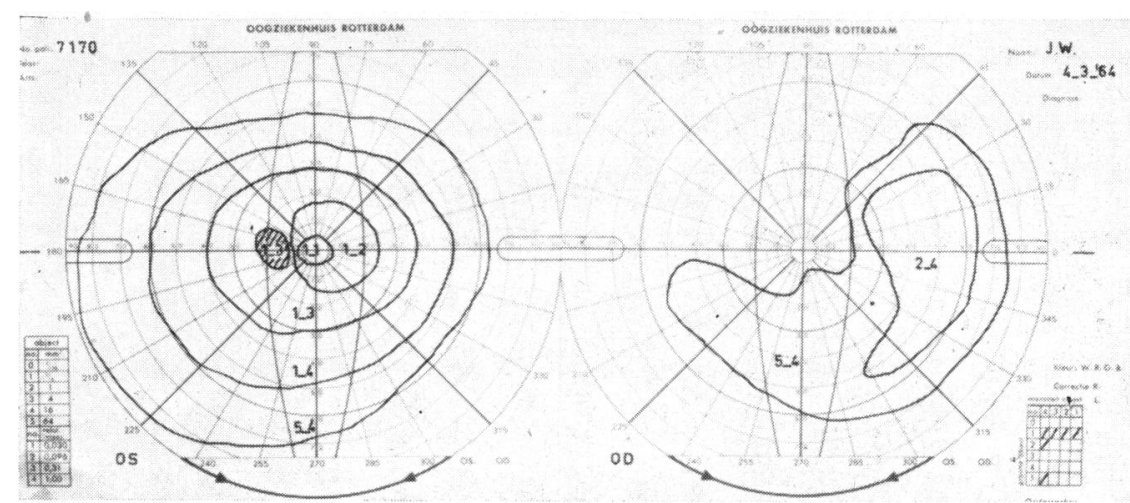

FIG. 4.-Marked loss of visual field of affected right eye. Normal field of left eye. 
Of the permanent teeth the following are present:

\begin{tabular}{l|l|l|l|l|l|l||l|l|l|l|l|l|l}
- & $\mathbf{M}_{1}$ & - & $\mathbf{P}_{1}$ & $\mathrm{C}$ & - & - & - & - & - & $\mathbf{P}_{1}$ & $\mathbf{P}_{2}$ & $\mathbf{M}_{1}$ & - \\
\hline $\mathbf{M}_{2}$ & $\mathbf{M}_{1}$ & - & $\mathbf{P}_{1}$ & $\mathrm{C}$ & $\mathrm{I}_{2}$ & $\mathrm{I}_{1}$ & $\mathrm{I}_{1}$ & $\mathrm{I}_{2}$ & $\mathbf{C}$ & $\mathbf{P}_{1}$ & - & $\mathbf{M}_{1}$ & $\mathbf{M}_{2}$
\end{tabular}

Besides the third molars anodontia is found of 10 permanent elements. Most of the permanent elements present microdontia. Many of them are yellow and decayed due to an enamelogenesis imperfecta. Some of the permanent teeth are still impacted, 7 temporary teeth are still present (Fig. 5).

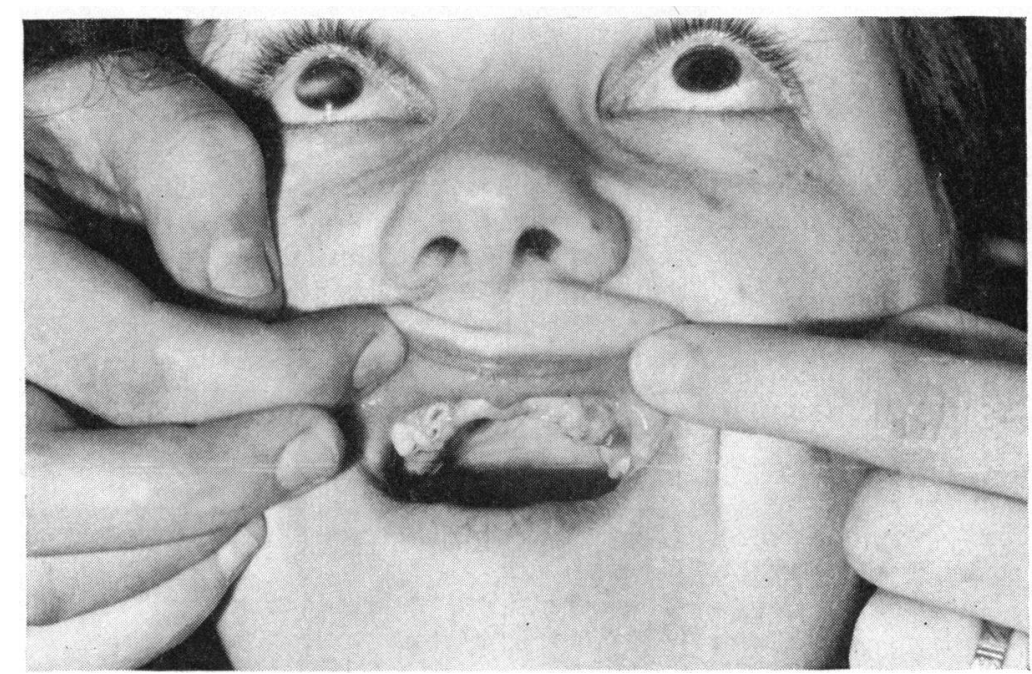

Fig. 5.-Oligodontia vera as present at the age of 16. Apart from the third molars, 10 permanent elements are missing. Most of the permanent elements are yellow and decayed, due to enamelogenesis imperfecta, and show microdontia.

Apart from the hypoplastic maxilla, the mandibula shows a hyperplasia, possible on an hereditary basis. The radiograph of the head shows further a dorsal position of the subnasale, a small apical base of the maxilla, and a large angle between the ramus horizontalis and ascendens of the mandibula (Fig. 6).

It is interesting to note that the patient's brother shows progenic mandibulas too, but without oligodontia vera."

Due to the existing anomalies of the anterior segment of the eye combined with developmental defects of the facial skull and the dental anomalies present, a tentative diagnosis was made of an incomplete form of Rieger's syndrome with oligodontia vera. However, in the course of a more detailed $x$-ray examination of the bones, we came upon a symmetrical developmental anomaly, the metacarpals IV and V in each of the hands being clearly dysplastic (Fig. 7). A similar anomaly, however, was not found in the feet.

Based upon these new facts, we were inclined to favour the diagnosis of dysplasia-oculodento-digitalis.

\section{Discussion}

The rupture of Descemet's membrane with subsequent swelling of the corneal stroma can be explained on the basis of a poor quality of endothelium and Descemet's membrane, but a traumatic origin is possible. Apart from ruptures of Descemet's 

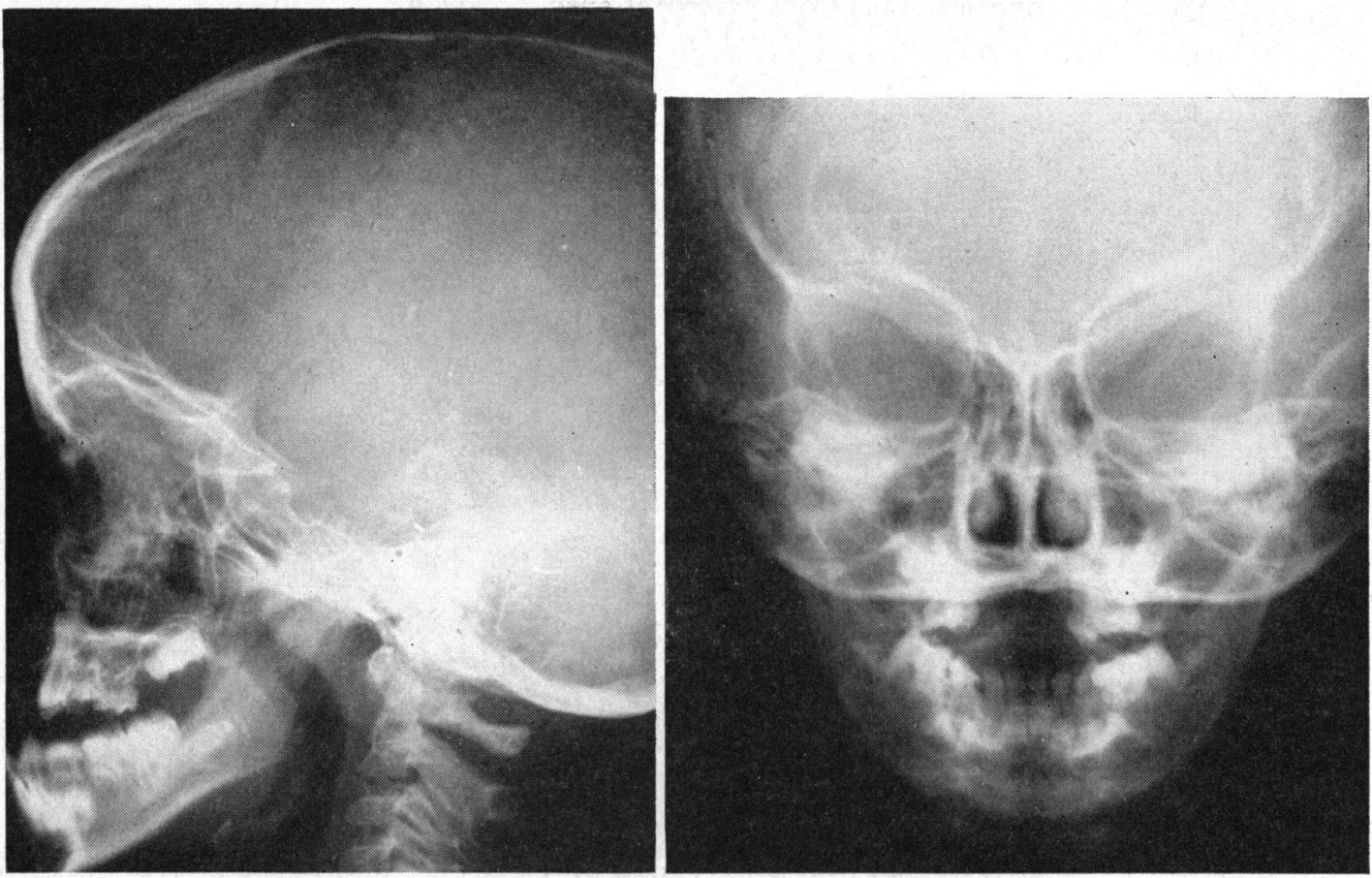

Fig. 6.-Radiographs taken at the age of 9. Hypoplastic maxilla, hyperplasia of the mandibula, large angle between horizontal and ascending ramus mandibularis.

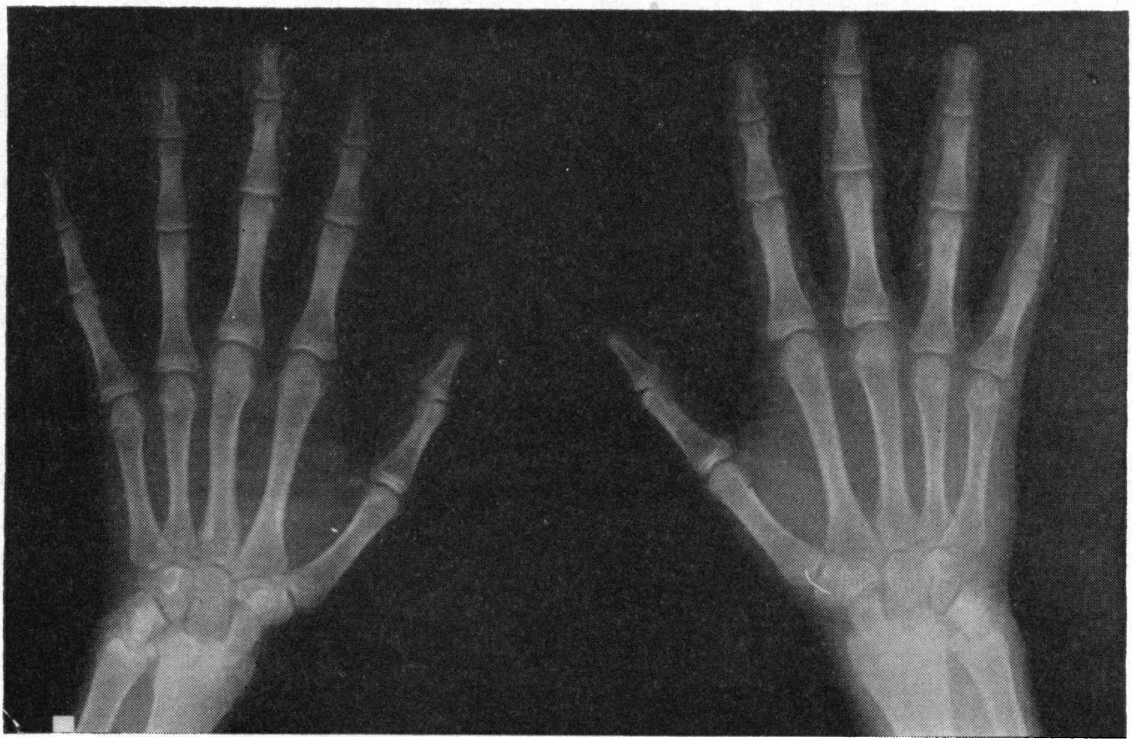

FIG. 7.-Dysplasia of metacarpals IV and V. 
membrane due to operative traumas (cataract surgery; cyclodialysis) and the occurrence due to stretching in hydrophthalmos and keratoconus, there is no literature to support the traumatic origin in our case.

Non-operative traumas have been reviewed by Balavoine (1953); only blunt traumas (forceps delivery) are mentioned as a relatively frequent cause. The extensive retrocorneal membrane found in our case, however, is not listed under any of the above-mentioned traumatic causes.

Apart from a traumatic dystrophy, we have to exclude in our case certain types of developmental anomalies of the cornea. Most of these, however, as well as the retrocorneal hyaline membranes, are congenital, bilateral, and are connected in some way or another with the dysplasia marginalis posterior (Mann, 1957), as they appear to be located mostly in the peripheral parts of the cornea.

Theodore (1944), however, describes 6 unilateral cases of congenital corneal dystrophy, two of which involved the central cornea. Nevertheless, the appearances described are unlike the dystrophy seen in our patient.

The same argument can be brought forward against the unilateral retrocorneal hyaline membrane described by Berliner (1941), found with other anomalies of the anterior segment of the eye and combined with syndactyly. Unfortunately, neither Theodore nor Berliner gives a gonioscopic description. Moreover, these authors do not provide any information concerning the condition of the skeleton and teeth.

Chandler's (1956) publication is worth mentioning as he describes a few cases of congenital dysgenesis of the anterior segment, in combination with glaucoma and unilateral endothelial corneal dystrophy. The description, however, does not fit the retrocorneal membrane found in our case.

The same holds for the description of Pietruschka's cases (1960)-extensive endothelial dystrophy found in a family in which glaucoma, hypoplasia iridis, abnormalities in the chamber angle, and high myopia are found. In this family, the corneal dystrophies are peripherally located and demonstrate a trend towards an extensive posterior marginal dysplasia.

One might consider ectodermal dysplasia in the differential diagnosis of this case, a syndrome in which both ectodermal and mesodermal anomalies of the anterior segment of the eye may occur-hypoplasia of the iris stroma and developmental anomalies of the chamber angle and glaucoma. Myopia is also reported to occur. However, ectodermal symptoms-hypotrichosis, poor quality of the hairs, decreased or even absent sweating, and anomalies of the outer ear-are not present in our patient. Moreover, skeletal anomalies are unknown in this syndrome.

To conclude: as far as a study of the literature goes, identical cases describing the occurrence of an acute extensive corneal dystrophy following a spontaneous (?) descemetolysis, have not been reported.

The second point of importance is the bluish scleral band. The bluish sclerae present in our patient had already attracted attention in childhood, the colour being so marked that the orthodontist asked for an examination by the internist in order to rule out the presence of an osteogenesis imperfecta! (Many of us will have been unaware that dental anomalies are not infrequently found in the brittle-bones syndrome.) 
Two questions stand out clearly:

(1) Does the blue scleral band bear a relation to the anomalies found in the anterior segment of the eye?

(2) If such a relationship is likely to exist (based on a study of the literature), does the existence of this blue sclera contribute to the differential diagnosis between an incomplete Rieger's syndrome with oligodontia vera on the one hand, and dysplasia oculo-dento-digitalis on the other?

Are there, by chance, additional symptoms present which might help in the final diagnosis of this case?

As dysplasia of the anterior segment of the eye is a relatively frequent and polymorphous feature, one would expect an abnormal development of the anterior sclera to be relatively common too. However, nothing is found in the text-books on this point, apart from the existence of blue sclerae in osteogenesis imperfecta (Duke-Elder (1964)). But our study of the literature has resulted in the finding of eleven cases (not including the present one) presenting a bluish scleral band; one more case has not so far been published (De Haas (1964)).

The cases are tabulated in Table I.

TABLE I

Details of Cases in the Literature

\begin{tabular}{|c|c|c|c|c|}
\hline $\begin{array}{l}\text { Case } \\
\text { No. }\end{array}$ & Authors & Main Ocular Symptoms & $\begin{array}{l}\text { Dental-Skeletal } \\
\text { Anomalies }\end{array}$ & Remarks \\
\hline 1,2 & $\begin{array}{l}\text { Collier } \\
(1962)\end{array}$ & $\begin{array}{l}\text { Dysplasia marginalis corneae } \\
\text { posterior, microcornea, } \\
\text { retrocorneal hyaline membranes }\end{array}$ & Not mentioned & $\begin{array}{l}\text { In first case: "no brittle- } \\
\text { bones syndrome present" }\end{array}$ \\
\hline 3 & $\begin{array}{l}\text { Durham } \\
\text { (1953) }\end{array}$ & Microcornea, infantile glaucoma & Not mentioned & Ehlers-Danlos syndrome \\
\hline 4,5 & $\begin{array}{l}\text { Gasteiger } \\
(1946)\end{array}$ & $\begin{array}{l}\text { Cornea plana, xerosis } \\
\text { conjunctivae }\end{array}$ & Not mentioned & $\begin{array}{l}\text { Anomaly present in } \\
\text { mother and daughter }\end{array}$ \\
\hline $6,7,8,9$ & $\begin{array}{l}\text { Falls } \\
\text { (1949) }\end{array}$ & $\begin{array}{l}\text { Family with various develop- } \\
\text { mental anomalies of anterior } \\
\text { segment of eye }\end{array}$ & Not mentioned & $\begin{array}{l}\text { Cases C-1, A-7, A-10, } \\
\text { and F-3 }\end{array}$ \\
\hline 10,11 & $\begin{array}{l}\text { Gedda and } \\
\text { Magistretti } \\
\text { (1959) }\end{array}$ & $\begin{array}{l}\text { Family with atrophia iridis and } \\
\text { various other signs of dysgenesis } \\
\text { camerae anterior }\end{array}$ & Not mentioned & Cases $V_{35}$ and $V_{78}$ \\
\hline 12 & $\begin{array}{l}\text { De Haas } \\
\text { (1964) }\end{array}$ & $\begin{array}{l}\text { Aplasia of anterior leaf of iris, } \\
\text { infantile glaucoma }\end{array}$ & Absent & \\
\hline
\end{tabular}

From this Table it is clear that bluish sclerae are relatively rare-apart from their place in the brittle-bones syndrome. But in all thirteen cases described (including the one under discussion), features of developmental anomalies of the anterior segment of the eye were present. Unfortunately, the existence of dental and/or skeletal malformation is mentioned only occasionally. As bluish sclerae or blue scleral bands have not been mentioned in dysplasia oculo-dento-digitalis, one would be inclined to consider the scleral anomaly found in the case under discussion as a factor in favour of the diagnosis of an incomplete Rieger's syndrome, rather 
than of an oculo-dento-digital dysplasia. However, the number of cases of the latter anomaly published so far is much too small to allow such a conclusion. There are, however, some more factors in favour of the diagnosis of an abortive form of Rieger's syndrome in our patient, i.e., the hyperplasia of Schwalbe's ring. This condition and the posterior marginal dysplasia of the cornea are, in fact, two different aspects of the same anomaly (Burian, Braley, and Allen, 1955). One of the factors against the diagnosis of an abortive form of Rieger's syndrome could be that the fully developed Rieger's syndrome is associated in most instances with microphthalmos, which is lacking here. This latter argument, however, might well be considered as a point in favour, supported by the hypoplasia of the iris stroma, the intactness of the pigment layer, the absence of holes in the iris, and the absence of a clear displacement of the pupil.

A more decisive argument in favour of Rieger's syndrome and against the oculodento-digital dysplasia, is the fact that both Meyer-Schwickerath, Grüterich, and Weijers (1957) and Gillespie (1964) mention typical small alae nasi with anteverted nostrils. In our case, however, the alae nasi are not small and the nose is rather plump, with the nostrils normally placed (see Figs 1 and 5). The same appearance of the nose is found in the case of 'the fully developed Rieger's syndrome by Lemmingson (1961) and by Frandsen (1964). As Frandsen, however, does not make a clear differentiation in his case between the two syndromes, it is necessary to collect material from earlier authors describing cases of Rieger's syndrome. Only a detailed description and a photographic study of the cases published so far will be able to decide whether the plump nose is a more or less compulsory feature of Rieger's syndrome.

\section{Summary}

The case history is discussed of a 16-year-old girl suffering from an acute corneal dystrophy due to a spontaneous descemetolysis. Apart from a dysgenesis of the anterior segment of the eye, glaucoma, blue sclerae (or bluish scleral band), myopia, oligodontia vera, and metacarpal dysplasia were also present. Differential diagnosis is discussed between the abortive form of Rieger's dysgenesis mesodermalis corneae et iridis and the oculo-dento-digital dysplasia.

I wish to acknowledge the encouragement and invaluable help given to me by Dr. P. J. Waardenburg, Arnhem, to whom I express my grateful thanks.

\section{REFERENCES}

Balavoine, C. (1953). Ann. Oculist. (Paris), 186, 111.

BerLiner, M. L. (1941). Arch. Ophthal., 26, 653.

Burian, H. M., Braley, A. E., and Allen, L. (1955). Ibid., 53, 767.

Chandler, P. A. (1956). Amer. J. Ophthal., 41, 607.

Collier, M. (1962). Ann. Oculist. (Paris), 195, 512.

Duke-Elder, Sir Stewart (1964). 'Congenital Deformities' in "System of Ophthalmology", vol. 3, pt 2, p. 539. Kimpton, London.

Durham, D. G. (1953). Arch. Ophthal. (Chicago), 49, 220.

Falls, H. F. (1949). Amer. J. Ophthal., 32, no. 6, pt 2, p. 41.

FrandSen, E. (1964). Acta ophthal. (Kbh.), 41, 757.

Gasteiger, H. (1946). Klin. Mbl. Augenheilk., 111, 247.

GedDa, L., and BérARd-Magistretti, S. (1959). Acta Genet. med. (Roma), 8, 39. 
Gillespie, F. D. (1964). Arch. Ophthal., 71, 187.

De HaAs, E. B. H. (1964). Personal communication.

HaGedOORN, A. (1937). Arch. Ophthal. (Chicago), 17, 223.

Lemmingson, W. (1961). Klin. Mbl. Augenheilk., 138, 96.

MANN, I. (1957). "Developmental Abnormalities of the Eye", 2nd ed. B.M.A., London.

Meyer-Schwickerath, G., Grüterich, E., and Weyers, M. (1957). Klin. Mbl. Augenheilk., 131, 18.

PietrusChKa, G. (1960). I I bid., 136, 794.

THEODORE, F. H. (1944). Arch. Ophthal. (Chicago), 31, 138. 